\title{
Methyl Radical Initiated Kharasch and Related Reactions
}

\author{
Nicholas D. C. Tappin, and Philippe Renaud* \\ University of Bern, Department of Chemistry and Biochemistry, Freiestrasse 3, 3012 Bern. \\ Email: philippe.renaud@dcb.unibe.ch
}

Supporting information for this article is available on the WWW under http://dx.doi.org/10.1002/adsc.201\#\#\#\#\#\#.

\begin{abstract}
An improved procedure to run halogen atom and related chalcogen group transfer radical additions is reported. The procedure relies on the thermal decomposition of di-tert-butylhyponitrite (DTBHN), a safer alternative to the explosive diacetyl peroxide, to produce highly reactive methyl radicals that can initiate the chain process. This mode of initiation generates byproducts that are either gaseous $\left(\mathrm{N}_{2}\right)$ or volatile (acetone and methyl halide) thereby facilitating greatly product purification by either flash column chromatography or distillation. In addition, remarkably simple and mild reaction conditions (refluxing EtOAc during 30 minutes under normal atmosphere) and a low excess of the radical precursor reagent ( 2.0 equivalents) make this protocol particularly attractive for preparative synthetic applications. This initiation procedure has been demonstrated with a broad scope since it works efficiently to add a range of electrophilic radicals generated from iodides, bromides, selenides and xanthates over a range of unactivated terminal alkenes. A diverse set of radical trap substrates exemplifies a broad functional group tolerance. Finally, di-tert-butyl peroxyoxalate (DTBPO) is also demonstrated as alternative source of tert-butoxyl radicals to initiate these reactions under identical conditions which gives gaseous byproducts $\left(\mathrm{CO}_{2}\right)$.
\end{abstract}

Keywords: radical reaction; atom transfer; radical initiation; chain reaction; carbohalogenation; haloalkylation; ATRA; alkene.

\section{Introduction}

The atom transfer radical addition (ATRA) process discovered by Kharasch in the 1940s is one of the most attractive processes to create carbon-carbon bonds under mild conditions and perfect atom economy (Scheme 1). ${ }^{[1-6]}$ In theory, such an efficient chain reaction requires only a tiny amount of a radical initiator when the process is favored by thermodynamic and polar effects. In practice, the initiation has proven to be a crucial element for the success of this reaction. Three strategies are commonplace to initiate ATRA processes: A carbonhalogen bond homolysis, B halogen atom abstraction, and $\mathbf{C}$ reductive single electron transfer. Curran has thoroughly demonstrated that the more reactive halides such as $\alpha$-iodocarbonyl compounds are among the best substrates to run ATRA reactions. ${ }^{[7-10]}$ For such derivatives, initiation using sun lamp irradiation was possible (strategy A). However, the generation of a small amount of iodine resulting from the homolysis of the C-I bond was found to inhibit ATRA chain propagation by regenerating the starting radical precursor iodide before the $\mathrm{C}$-centered radical could add onto the alkene. Adding hexamethylditin that reacts spontaneously with elemental iodine to form $\mathrm{Me}_{3} \mathrm{SnI}$ effectively solved this problem but led to product contamination with tin residues. ${ }^{[11]}$ Photoinitiation in the presence of a sensitizer such $p$ anisaldehyde was found to work well with highly activated radical precursors such as bromomalonate derivatives, $\mathrm{CCl}_{4}$, and perfluorohexyl iodide. ${ }^{[12]}$
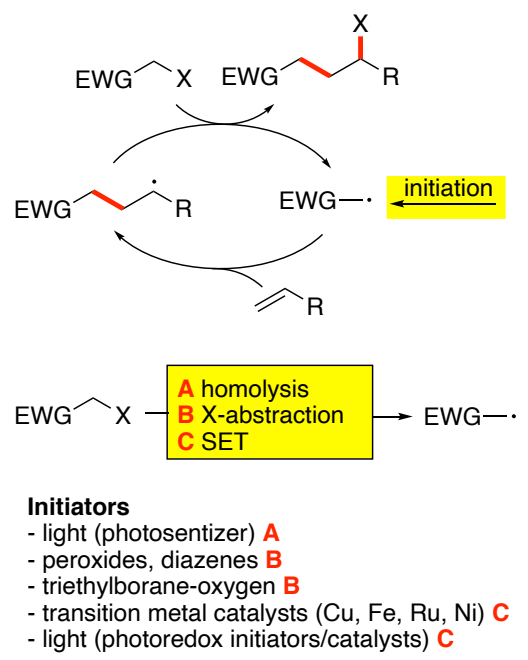

Scheme 1. ATRA process. Key approaches for the initiation step.

Kharasch in his seminal work used mainly strategy B with diacetyl peroxide as a source of methyl radicals. ${ }^{[5]}$ However, this peroxide is explosive and shock sensitive, and has therefore been generally replaced by the more stable dilauroyl peroxide (DLP). ${ }^{[13]}$ The DLP approach has proved to be reliable but the thermal decomposition products of DLP including lauric acid, n-docosane and undecyl laurate, ${ }^{[14]}$ as well as lauroyl halide from productive initiation, often contaminate the products and difficult (sometimes multiple) purifications by column chromatography are required to obtained analytically pure ATRA products. This byproduct contamination 
has also been observed when DLP was used to initiate the highly efficient xanthate transfer reactions developed over the last two decades by Zard and coworkers. ${ }^{[15,16]}$ One remarkably successful solution has been to initiate with triethylborane and oxygen, which works via transient ethyl radicals (strategy B). ${ }^{[17-19]}$ However the pyrophoric character of triethylborane, and inherent incompatibility with $\alpha$ halo- and $\alpha$-chalcoketones, ${ }^{[20,21]}$ have made this strategy less attractive. The use of transition metal catalysis ( $\mathrm{Fe}, \mathrm{Cu}, \mathrm{Ru}, \mathrm{Ni}$ for instance) is also a popular way of initiating (and often catalyzing) ATRA processes, ${ }^{[22-27]}$ this approach involves an initial innersphere electron transfer (strategy $\mathbf{C}$ ) and is particularly suitable for reactions onto activated alkenes such as styrene derivatives. More recently, visible lightpromoted electron transfers (strategy C) have been reported in the presence of diverse, often expensive, transition metal catalysts. ${ }^{[28-36]}$ Despite all these studies, the need of a simple and broadly applicable method to run ATRA reactions remains highly needed. Ideally, the reaction should work with a wide range of reactive - and less reactive - substrates and reagents under mild reaction conditions that avoid the use of expensive or toxic metals and the formation of byproducts which are difficult to remove.

Approaches $\mathbf{A}$ and $\mathbf{C}$ can provide very efficient continuous solutions for the ATRA reaction. However, based on their mechanism of action, they are not expected to be applicable to a broad range of radical precursors possessing different redox potentials and photochemical properties. On the other hand, method B involving classical halogen transfer processes is expected to behave in a highly predictable manner and its efficiency is governed by the difference of the $\mathrm{C}-\mathrm{X}$ bond dissociation energies between the radical precursor and the halide or chalcogenide product resulting from initiation. In order to maximize the thermodynamic aspect of the initial atom transfer, the use of the least stable alkyl radical, i.e. the methyl radical, is an optimal choice insuring a fast halogen transfer step with few chain-breaking events. Besides fragmentation of diacetyl peroxide employed in Kharasch's seminal work, methyl radicals are also generated by fragmentation of tert-butoxyl radicals. ${ }^{[37]}$ The use of di-tert-butyl peroxide was not considered as an option since temperatures $\geq 120^{\circ} \mathrm{C}$ are required for its homolysis. ${ }^{[38,39]}$ Interestingly, the thermal homolytic scission of di-tert-butyl hyponitrite $(\mathrm{DTBHN})^{[40,41]}$ takes place facilely at moderate temperatures $\left(40-70{ }^{\circ} \mathrm{C} ; \mathrm{t}_{1 / 2}=29 \mathrm{~min}\right.$ at $65^{\circ} \mathrm{C}$, neat) to result in the simultaneous formation of two tertbutoxyl radicals and extrusion of molecular nitrogen. A first order rate in [DTBHN] with constant of $k_{\mathrm{f}}=$ $3.85-4.00 \times 10^{4} \mathrm{~s}^{-1}$ was measured for this decomposition at $65{ }^{\circ} \mathrm{C}$ in isooctane. ${ }^{[40]} \beta$ Fragmentation of the tert-butoxyl radical to acetone and a methyl radical ${ }^{[37]}$ takes place spontaneously and quickly at ambient temperatures $\left(k_{\beta}=1.4 \times 10^{4} \mathrm{~s}^{-1}\right.$ in benzene at $\left.22{ }^{\circ} \mathrm{C}\right),{ }^{[42]}$ and is sped up with heating $\left(k_{\beta}\right.$ $=1.1 \times 10^{5} \mathrm{~s}^{-1}$ in cumene at $\left.60^{\circ} \mathrm{C}\right) .{ }^{[43]}$ Even more interesting, this fragmentation is accelerated in polar $\left(k_{\beta}=6.4 \times 10^{4} \mathrm{~s}^{-1}\right.$ in acetonitrile at $\left.22{ }^{\circ} \mathrm{C}\right)$ and protic solvents $\left(k_{\beta}=1.4 \times 10^{6} \mathrm{~s}^{-1}\right.$ in water at $\left.22^{\circ} \mathrm{C}\right){ }^{[42]} \mathrm{Up}$ to now, most radical initiations using DTBHN involve rapid reactions of tert-butoxyl radicals with oxophilic species such as organoboron and ditin derivatives as well as hydrogen atom donors such as tin hydrides and silanes (Scheme 2, top, grey). ${ }^{[41]}$ However, when no such species is present in the reaction mixture, DTBHN is expected to be a good source of methyl radicals and therefore a powerful system to initiate halogen atom transfer process from a variety of radical precursors. To the best of our knowledge, the DTBHN-methyl radical mediated initiation has only been used by Trauner and coworkers for a conversion of a xanthate to a bromide (Scheme 2, middle).$^{[44,45]}$ Here, we report that DTBHN is an excellent general initiator for ATRA processes under simple, mild, and clean (only volatile initiator byproducts) reaction conditions (Scheme 2, bottom). Here, only a small excess of the radical precursor

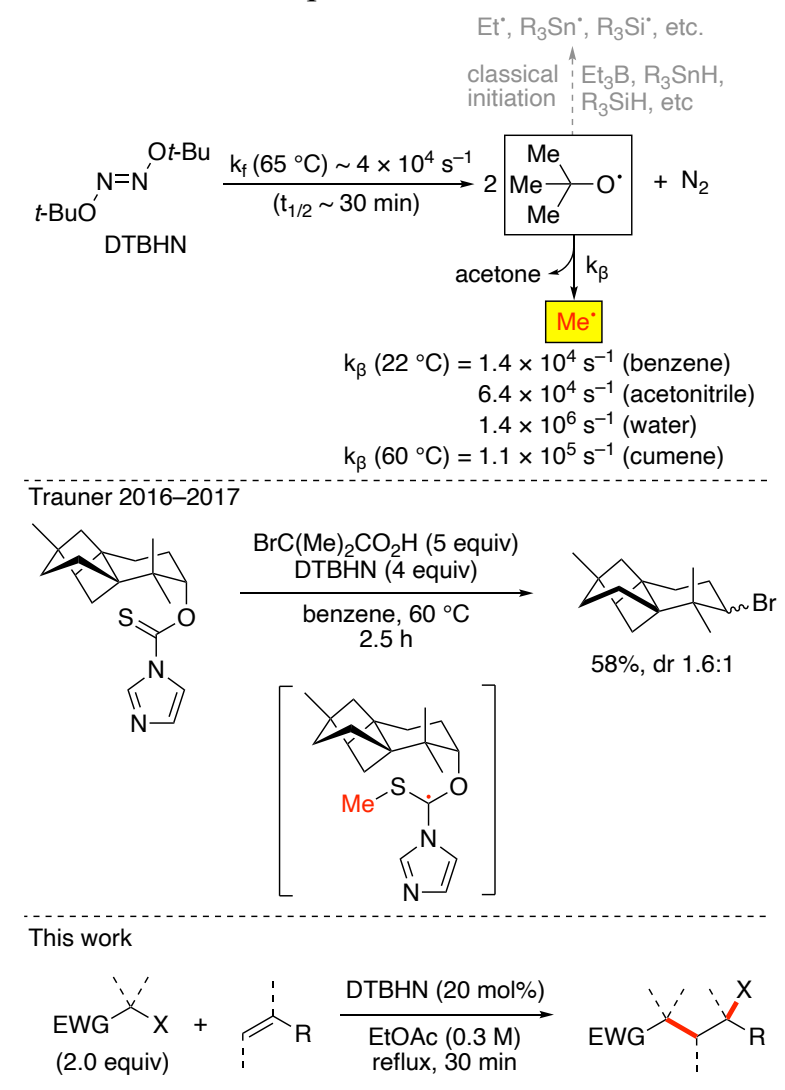

Scheme 2. Thermal decomposition of DTBHN as a source of methyl radicals.

reagent (2.0 equiv) relative to the substrate is employed avoiding the frequently reported and wasteful excess (typically $\geq 5.0$ equiv).

\section{Results and discussion}

Preliminary experiments with different radical precursors. The methyl radical initiation was first attempted for iodine atom transfer reactions which is a 
high-performing manifold for the Kharasch reaction. As polar solvents were expected to favor $\beta$-scission, ${ }^{[42]}$ we selected the environmentally benign EtOAc as a solvent that has a reflux temperature matching a short half-life of DTBHN. ${ }^{[40]}$ Initial studies were performed with 2.0 equivalents of 1 -undecene 1a using a short reaction time of 30 minutes. Reaction with ethyl iodoacetate 2a gave ATRA product 3a in high yields between 5-20 mol\% loadings of DTBHN (Table 1, Entry 1). Reproducibility and yields were best for DTBHN loadings over $10 \mathrm{~mol} \%$ and had plateaued (and were very slightly eroded) by $20 \mathrm{~mol} \%$. The rate constants for the halogen atom transfer from the starting halide to a primary alkyl radical are also given in Table $1,{ }^{[46]}$ to show that yields of $\mathbf{3}$ correlate well with transfer rates from 2. More challenging radical precursors were then tested in a systematic progression (Entries 1-8). Bromine atom transfer from ethyl bromoacetate $\mathbf{2} \mathbf{b}^{[5]}$ furnished $\mathbf{3 b}$ in moderate $25 \%$ yield (Entry 2). The yield reached $33 \%$ by adding another $20 \mathrm{~mol} \%$ of DTBHN demonstrating that the chain reaction is inefficient presumably due to the slow bromine atom transfer propagation step. Phenylseleno group transfer reaction behaved poorly for the ester precursor $\mathbf{2 c}$ (entry 3 ) but xanthate group transfer performed well with the ester $\mathbf{2 d}$ (entry 4 , $90 \%$ ). A similar trend was observed for the acetonitrile derivatives $\mathbf{2 e}-\mathbf{2 h}$. The iodide $\mathbf{2 e}$, a typical iodineATRA radical precursor, gave an anticipated good yield for iodide 3e (entry 5, 78\%), as did the bromoacetonitrile $2 \mathrm{f}$ to furnish $\mathbf{3 f}$ in $70 \%$ yield under our standard conditions (entry 6). Phenylselenoacetonitrile $\mathbf{2 g}$ gave $\mathbf{3 g}$ in low yield (entry 7) and reaction of the xanthate $\mathbf{2 h}$ with $\mathbf{1 a}$ delivered $\mathbf{3 h}$ in excellent yield (entry 8). Less reactive iodides such as the pinacol boronic ester $2 \mathbf{i}^{[47]}$ and the sulfone $\mathbf{2} \mathbf{j}^{[48-50]}$ afforded the ATRA products in moderate to excellent yields (entries 9 and 10). The unstable heat and light sensitive 2-iodoacetophenone $\mathbf{2 k}$ did not afford cleanly the iodide $\mathbf{3 k}$ (entry 11 ). On the other hand, the corresponding bromoketone $2 \mathbf{I}^{[1,52]}$ did provide 31 in $50 \%$ yield (entry 12). Again, the xanthate $\mathbf{2 m}$ added to $\mathbf{1 a}$ in a quantitative manner (entry 13). The crude products of all reactions depicted in Table 1 were easy to purify by column chromatography, in sharp contrast to the same product mixtures prepared using DLP as an initiator that are contaminated by the aforementioned non-volatile decomposition byproducts. ${ }^{[14,53-55]}$

Table 1. Identification of radical precursor $(\mathbf{2 a}-\mathbf{m})$ scope with 1 -undecene $\mathbf{1 a} .^{[\mathrm{a}]}$

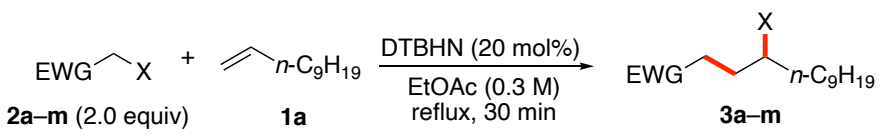

\begin{tabular}{|c|c|c|c|c|c|c|c|}
\hline \multirow[t]{2}{*}{ Entry $^{[\mathrm{a}]}$} & \multicolumn{3}{|c|}{ Radical Precursor } & \multirow[t]{2}{*}{$k_{\mathrm{T}}\left[\mathrm{M}^{-1} \mathrm{~s}^{-1}\right]$} & \multirow{2}{*}{$\begin{array}{l}\text { Rate } \\
\text { Ref. }\end{array}$} & \multirow[t]{2}{*}{ Product } & \multirow[t]{2}{*}{ Yield $\mathbf{3}^{[\mathrm{b}]}$} \\
\hline & & EWG & $\mathrm{X}$ & & & & \\
\hline 1 & $2 a$ & $\mathrm{CO}_{2} \mathrm{Et}$ & $\bar{I}$ & $2.6 \times 10^{7}$ & [46] & $\mathbf{3 a}$ & $83 \%, 87 \% \%^{[\mathrm{c}]}$ \\
\hline 2 & $2 b$ & $\mathrm{CO}_{2} \mathrm{Et}$ & $\mathrm{Br}$ & $7 \times 10^{4}$ & [46] & $\mathbf{3 b}$ & $25 \%, 33 \% \%^{[\mathrm{d}]}$ \\
\hline 3 & $2 c$ & $\mathrm{CO}_{2} \mathrm{Et}$ & $\mathrm{SePh}$ & $1.0 \times 10^{5}$ & {$[56]$} & $3 \mathbf{c}$ & $<5 \%$ [e] \\
\hline 4 & $2 d$ & $\mathrm{CO}_{2} \mathrm{Et}$ & $\mathrm{SC}(\mathrm{S}) \mathrm{OEt}$ & & & 3d & $90 \%$ \\
\hline 5 & $2 e$ & $\mathrm{CN}$ & I & $1.7 \times 10^{9}$ & [46] & $3 \mathbf{e}$ & $78 \%$ \\
\hline 6 & $2 f$ & $\mathrm{CN}$ & $\mathrm{Br}$ & $3 \times 10^{6}$ & [57] & $3 f$ & $70 \%$ \\
\hline 7 & $2 \mathrm{~g}$ & $\mathrm{CN}$ & $\mathrm{SePh}$ & $2.3 \times 10^{5}$ & {$[56]$} & $3 g$ & $13 \%$ \\
\hline 8 & $2 h$ & $\mathrm{CN}$ & $\mathrm{SC}(\mathrm{S}) \mathrm{OEt}$ & & & $3 h$ & $87 \%$ \\
\hline 9 & $2 \mathbf{i}$ & Bpin & I & & & $3 \mathbf{i}$ & $51 \%$ \\
\hline 10 & $2 \mathbf{j}$ & $\mathrm{SO}_{2} \mathrm{Ph}$ & I & & & $3 \mathbf{j}$ & $59 \%, 80 \% 0^{[\mathrm{d}]}$ \\
\hline 11 & $2 \mathbf{k}$ & $\mathrm{C}(\mathrm{O}) \mathrm{Ph}$ & I & & & $3 \mathbf{k}$ & $<10 \%{ }^{[\mathrm{e}]}$ \\
\hline 12 & 21 & $\mathrm{C}(\mathrm{O}) \mathrm{Ph}$ & $\mathrm{Br}$ & & & 31 & $41 \%, 50 \% 0^{[\mathrm{d}]}$ \\
\hline 13 & $2 \mathrm{~m}$ & $\mathrm{C}(\mathrm{O}) \mathrm{Ph}$ & $\mathrm{SC}(\mathrm{S}) \mathrm{OEt}$ & & & $3 \mathrm{~m}$ & $94 \%$ \\
\hline
\end{tabular}

[a] All reactions were performed on $1.0 \mathrm{mmol}$ of 1-undecene 1a and $2.0 \mathrm{mmol}$ of the radical precursor 2a-m, with technical grade EtOAc, without any drying of solvents or reagents under air atmosphere (no inert gas). The reaction mixture was heated under reflux for $30 \mathrm{~min}$ and concentrated in vacuo for direct purification by silica-gel flash column chromatography. [b] Isolated yields. [c] $10 \mathrm{~mol} \%$ DTBHN. [d] $2 \times 20 \mathrm{~mol} \%$ DTBHN, $2 \times 30 \mathrm{~min}$ reaction time. [e] Not characterized.

Scope of the method. Having established that a wide range of radical precursors could be added over 1 -substitued alkenes, more functionalized alkenes as well as different radical precursors were tested. The wealth of examples presented in Scheme 3 demonstrates the generality of this method. Alcohols protected as esters, Weinreb amides, and 1,2-cisalkenes all underwent iodine-ATRA with high yields (Scheme 3, 4-8) except for $\mathrm{ICH}_{2} \mathrm{Bpin}$ which furnished $\mathbf{5}$ in a modest $43 \%$ yield. Bromine-ATRA with dimethyl 2-bromomalonate $\mathbf{2 p}$ and $\mathrm{BrCH}_{2} \mathrm{CN}$ 2f provided $\mathbf{9}$ and $\mathbf{1 0}$ in excellent yields. The 2methylated bromomalonate $\mathbf{2 q}$ was allowed to react with the bromide 1d affording $\mathbf{1 1}$ in 30\% yield along with $43 \%$ of recovered $1 \mathrm{~d}$. The low yield is unlikely to be due to steric hinderance of the radical generated from $2 q$ since other groups have reported good results with this radical precursor. ${ }^{[12]}$ Conversion became high 
and yield increased to $44 \%$ with $2 \times 20$ mol\% DTBHN. The analogous selenomalonate $2 \mathbf{r}$, reacted with $\mathbf{1 d}$ and $\mathbf{1 g}$ to give 12 and 13 in improved $75 \%$ and $62 \%$ yields, respectively. The efficacy of the selenophenyl group transfer reaction with $\mathbf{2 q}$ relative to the monoester and nitrile derivatives $\mathbf{2 c}$ and $\mathbf{2 g}$ (Table 1, entries 3 and 7) is rationalized by the faster group transfer process $\left(k_{\mathrm{T}}\right.$ $\left.=8 \times 10^{5} \mathrm{M}^{-1} \mathrm{~s}^{-1}\right){ }^{[56]}$ Finally, challenging xanthate transfer reactions involving the formation of tertiary xanthates were attempted with cyclic exo-methylene radical traps and $\alpha$-ester and $\alpha$-ketone xanthates $\mathbf{2 d}$ and $\mathbf{2 m}$. The tertiary xanthates $\mathbf{1 4}$ and $\mathbf{1 5}$ were obtained in moderate $48 \%$ and $49 \%$ yields. Zard has reported a similar yield for the DLP-initiated xanthate transfer onto $N$-Boc protected 4-exo-methylenepiperidine. ${ }^{[58]}$

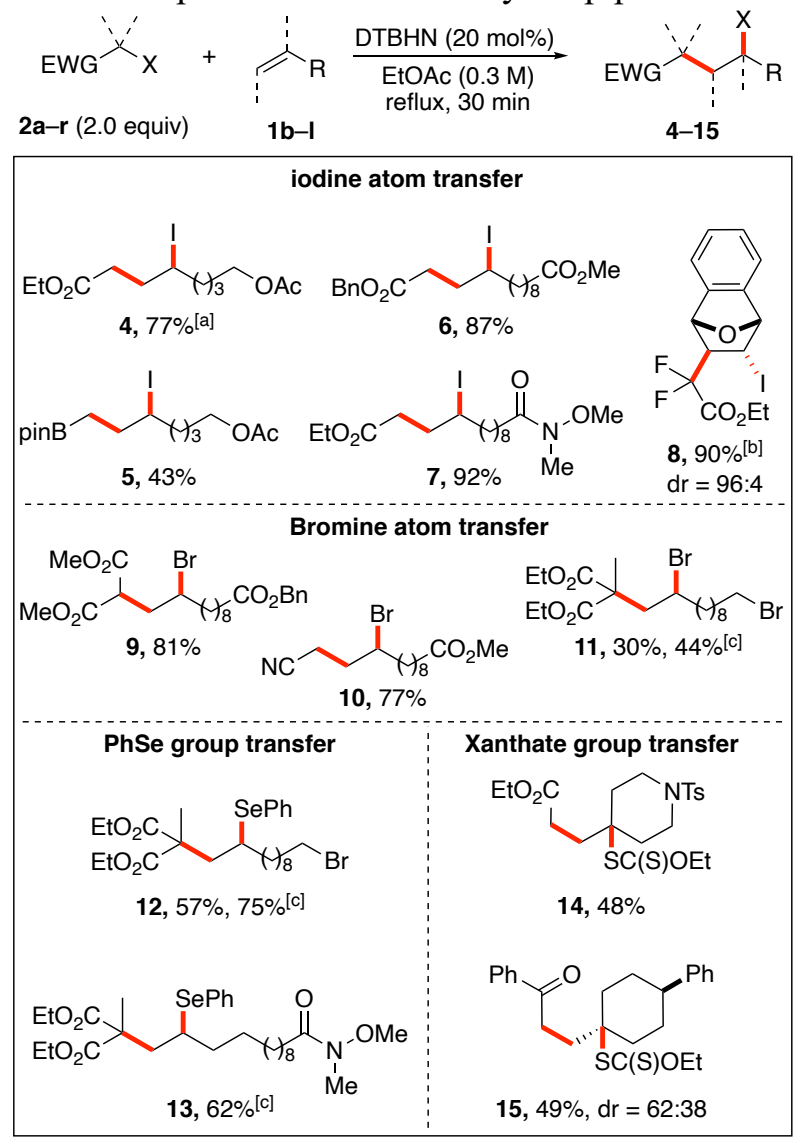

Scheme 3. Scope of the DTBHN initiated ATRA reactions. All reactions were performed as described in Table 1. Isolated yields are reported. [a] With $10 \mathrm{~mol} \%$ DTBHN. [b] Yield of major diastereoisomer; the two diastereoisomers were easily separated by flash column chromatography, (see SI for details). [c] $2 \times 20 \mathrm{~mol} \% \mathrm{DTBHN}, 2 \times 30 \mathrm{~min}$ reaction time.

Preparation of tertiary iodides and lactones. Due to the instability of tertiary iodide under most reactions conditions reported for ATRA reactions (light, heat), iodine ATRA-reactions involving the formation of a tertiary iodides have so far only been achieved at room temperature using triethylborane ${ }^{[59-61]}$ and $\mathrm{Mn}_{2}(\mathrm{CO})_{10}{ }^{[62]}$ initiation. Surprisingly, running the reaction between the protected 4-methylenepiperine $\mathbf{1 h}$ and ethyl 2-iodoacetate $\mathbf{2 a}$ under our mild DTBHN conditions afforded the tertiary iodide $\mathbf{1 6}$ in an excellent 91\% yield (Scheme 4, top). Its structure was confirmed by single crystal X-ray crystallography. When the same reaction was performed with methylenecyclohexane derivatives $\mathbf{1 i}-\mathbf{k}$, the intermediate tertiary iodides were spontaneously converted into the lactones $\mathbf{1 7 i - k}$ with respectable 76$81 \%$ yields (Scheme 4 , bottom). The reaction of methylenecyclohexane $\mathbf{5 i}$ with $\mathbf{2 a}$ was scaled up to 10 mmol without yield depreciation for the formation of $\mathbf{1 7 k}(79 \%)$ after distillation. Such lactonization processes were already observed by Kharasch in his seminal work on bromine ATRA but requires heating at $\geq 160{ }^{\circ} \mathrm{C}$, ${ }^{[5]}$ by Kraus and Landgrebe using iodostannylester, ${ }^{[63]}$ and by Curran with iodoesters and iodomalonate derivatives. ${ }^{[7,10,64]}$ This radical-ionic sequence has also been reported for ethyl iodoacetate ${ }^{[65-67]}$ and iodoacetic acid ${ }^{[68]}$ metal catalyzed ATRA processes.
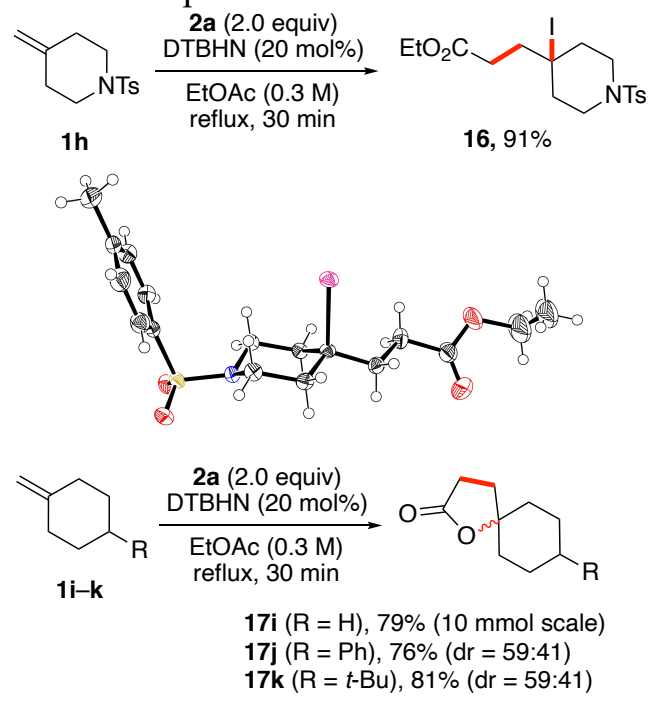

Scheme 4. Iodine ATRA reaction leading to tertiary iodides and lactones.

Radical cyclizations. In order to further showcase this initiation method, the iodine atom transfer cyclizations depicted in Scheme 5 were investigated. Iodoacetate 18 could be converted in good yield to the lactone 19 in agreement with light-ditin, ${ }^{[64]}$ and DLP procedures. ${ }^{[13]}$ An intermolecular radical additioncyclization sequence with a perfluoroalkyl iodide $\mathbf{2 s}$ was employed to convert $\mathbf{2 0}$ to the cyclopentane $\mathbf{2 1}$ in 94\% yield.

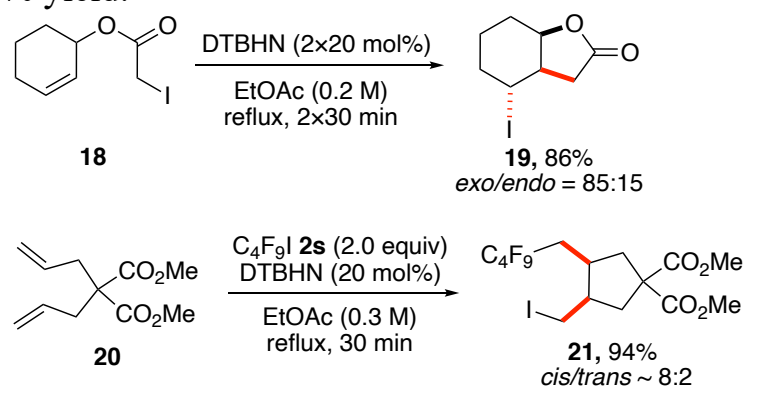

Scheme 5. DTBHN initiated iodine atom transfer cyclization. 
Mechanistic investigation. At the beginning of this project, we hypothesized that the initiation with DTBHN will involve the highly reactive methyl radical. In order to get insight into the mechanism and to confirm the involvement of methyl radicals, the reaction was monitored by NMR. The reaction between 2a and 1-undecene (1a) was performed in a sealed tube with $\mathrm{C}_{6} \mathrm{D}_{6}$ as a solvent. NMR analysis of an aliquot revealed a ${ }^{13} \mathrm{C}$-NMR signal at $-24.4 \mathrm{ppm}$ corresponding to MeI (see SI). In the ${ }^{1} \mathrm{H}-\mathrm{NMR}$, a singlet at $1.51 \mathrm{ppm}$ was present. Upon addition of commercial MeI to the reaction aliquot, a growth in intensity of the peak at $1.51 \mathrm{ppm}$ was observed confirming the formation of methyliodide. The formation of acetone resulting from the fragmentation of the intermediate tert-butoxyl radical could also be observed at $1.61 \mathrm{ppm}^{[69]}$ in the ${ }^{1} \mathrm{H}-\mathrm{NMR}$ spectrum of the reaction.

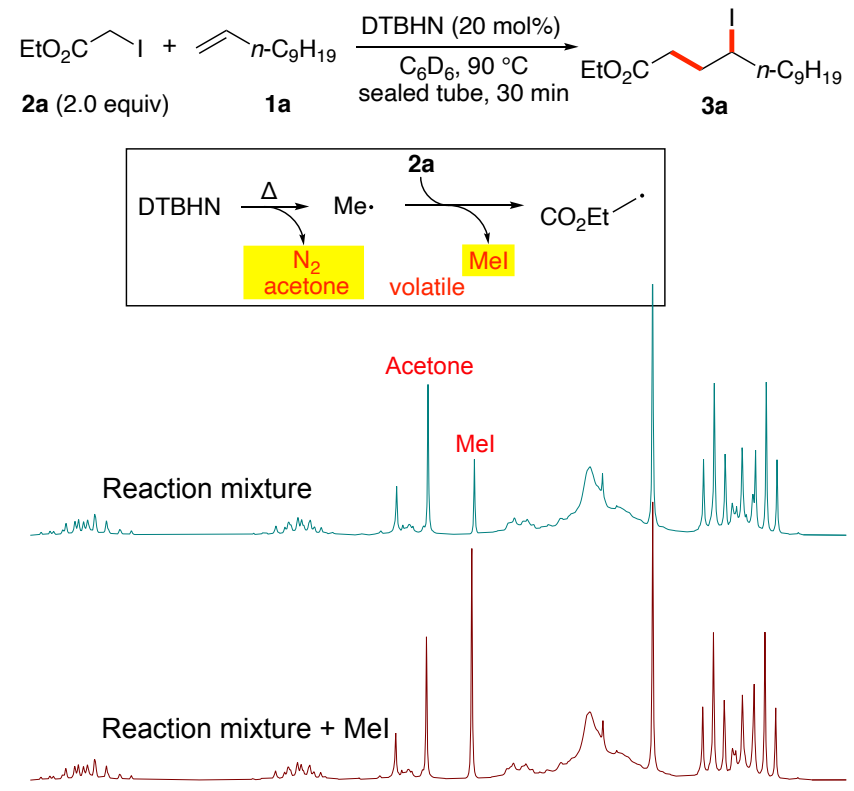

Scheme 6. Mechanism of the initiation process. ${ }^{1} \mathrm{H}-\mathrm{NMR}$ evidence for the formation of $\mathrm{MeI}$ and acetone during the reaction.

Initiation with di-tert-butyl peroxyoxalate. As an alternative to DTBHN for low temperature generation of tert-butoxyl radical, the easily prepared di-tertbutylperoxyoxalate (DTBPO) was tested. This compound has been recently used in our group for efficient tert-butoxyl radical mediated initiation of reactions involving organoborane precursors. ${ }^{[0,71]}$ Its decomposition as well as the initiation process is also expected to provide exclusively gaseous $\left(\mathrm{CO}_{2}\right)$ and volatile (MeI, acetone) byproducts (Scheme 7, top). When used in place of DTBHN for the iodine-ATRA reaction between $\mathbf{2 a}$ and the unsaturated benzoate $\mathbf{1 b}$, I-ATRA product 22 was obtained in $70 \%$ yield (Scheme 7, bottom) in full accordance with the DTBHN initiated processes seen in Table 1 and Scheme 3.

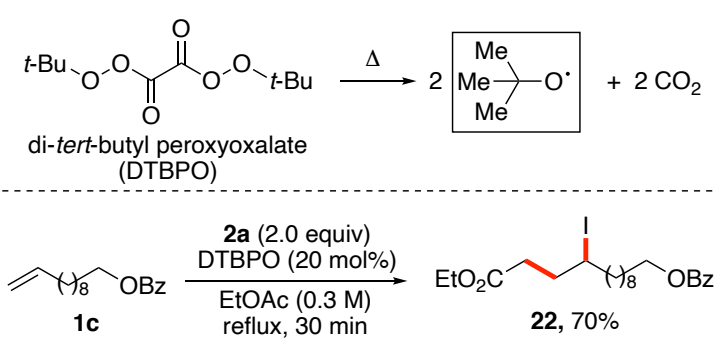

Scheme 7. DTBPO initiated iodine-ATRA reaction.: another clean initiation procedure.

\section{Conclusion}

A simple, mild and generally applicable procedure for halogen ATRA and related reactions has been developed. The use of DTBHN (or DTBPO) allows efficient initiation involving atom/group transfer processes, mediated by methyl radicals, at moderate temperature. The main advantage of this approach is the absence of product contamination caused by the initiation thus greatly facilitating product purification. Indeed, the byproducts of initiation are either gaseous $\left(\mathrm{N}_{2}\right.$ or $\left.\mathrm{CO}_{2}\right)$ or volatile (acetone, methyl iodide). Under these conditions, efficient and clean radical chain reactions can occur without the assistance of either toxic or expensive metal additives. In contrast to photoinitiated processes, thermal initiation with DTBNH is easily scalable as demonstrated by running the reaction on $10 \mathrm{mmol}$ scale without the need to modify the reaction conditions. We believe that the simplicity of this method will make it attractive for application of ATRA reactions in a broad of organic synthesis such as the synthesis of natural and biologically active products, preparation of novel material, and even construction of all kinds of molecular devices. In all these types of applications, purification is often a major problem for the delivery of high-quality material.

\section{Experimental Section}

Precautions: The preparation and manipulation of $\mathrm{DTBHN}^{[41]}$ and DTBPO ${ }^{172]}$ must be conducted behind a blast shield. DTBHN has been reported to be insensitive to scratching and is considered as handleable. ${ }^{[40]}$ DTBPO is sensitive to scratching and shock: ${ }^{[73]}$ Ear defenders, face shield, and thick leather gloves should be mandatory, in addition to standard PPE, as well as restrictions in quantities. Once in solution peroxides are safer: during this work no explosions occurred. For more information on working with peroxides consult the appropriate literature. ${ }^{[74]}$

See the SI for full experimental details. A representative procedure is given below.

Preparation of 3a. Under air atmosphere (no inert gas protection required), 1-undecene $1 \mathrm{a}(0.21 \mathrm{~mL}, 1.0 \mathrm{mmol})$, ethyl 2-iodoacetate $2 \mathrm{a}(0.24 \mathrm{~mL}, 2.0 \mathrm{mmol})$, and EtOAc (technical grade, $3.3 \mathrm{~mL}, 0.3 \mathrm{M}$ ) were loaded into a $10 \mathrm{~mL}$, 1-neck, round bottom flask equipped with a cold finger. DTBHN (35 mg, $20 \mathrm{~mol} \%$ ) was added in one portion to the flask which was then plunged into a $90{ }^{\circ} \mathrm{C}$ pre-heated oil bath. The reaction was heated under reflux for $30 \mathrm{~min}$. After concentration in vacuo, to the crude residue was purified by 
flash column chromatography to afford $\mathbf{3 a}$ as a clear oil (306 $\mathrm{mg}, 0.831 \mathrm{mmol}, 83 \%)$. $\mathrm{R}_{f}=0.45(8 \%$ EtOAc/heptanes $){ }^{1} \mathrm{H}$ NMR $\left(300 \mathrm{MHz}, \mathrm{CDCl}_{3}\right): \delta 4.14(\mathrm{q}, J=7.1 \mathrm{~Hz}, 2 \mathrm{H}), 2.74-$ $2.33(\mathrm{~m}, 2 \mathrm{H}), 2.19-2.00(\mathrm{~m}, 2 \mathrm{H}), 1.98-1.79(\mathrm{~m}, 1 \mathrm{H}), 1.71$ (ddt, $J=14.5,10.2,5.1 \mathrm{~Hz}, 1 \mathrm{H}), 1.55-1.46(\mathrm{~m}, 1 \mathrm{H}), 1.46$ $-1.36(\mathrm{~m}, 1 \mathrm{H}), 1.36-1.20(\mathrm{~m}, 15 \mathrm{H}), 0.91-0.85(\mathrm{~m}, 3 \mathrm{H})$. ${ }^{13} \mathrm{C} \mathrm{NMR}\left(75 \mathrm{MHz}, \mathrm{CDCl}_{3}\right): \delta 172.7\left(\mathrm{C}_{\mathrm{q}}\right), 60.5\left(\mathrm{CH}_{2}\right), 40.8$ $\left(\mathrm{CH}_{2}\right), 38.4(\mathrm{CH}), 35.5\left(\mathrm{CH}_{2}\right), 34.4\left(\mathrm{CH}_{2}\right), 31.9\left(\mathrm{CH}_{2}\right), 29.52$ $\left(\mathrm{CH}_{2}\right), 29.48\left(\mathrm{CH}_{2}\right), 29.45\left(\mathrm{CH}_{2}\right), 29.3\left(\mathrm{CH}_{2}\right), 28.8\left(\mathrm{CH}_{2}\right)$, $22.7\left(\mathrm{CH}_{2}\right), 14.2\left(\mathrm{CH}_{3}\right), 14.1\left(\mathrm{CH}_{3}\right)$. IR (thin film): $v_{\max }=$ $1733(\mathrm{~s}) \mathrm{cm}^{-1}$. Only the characteristic carbonyl stretch of the acyclic ester is reported. HRMS (ESI): Calculated for $\mathrm{C}_{15} \mathrm{H}_{30} \mathrm{O}_{2} \mathrm{I}[\mathrm{M}+\mathrm{H}]^{+}:$369.1285. Found: 369.1284.

\section{Acknowledgements}

We thank the Swiss National Science Foundation (grant 200020_172621) for financial support.

\section{References}

[1] M. S. Kharasch, E. V. Jensen, W. H. Urry, Science 1945, $102,128-128$.

[2] M. S. Kharasch, W. H. Urry, E. V. Jensen, J. Am. Chem. Soc. 1945, 67, 1626-1626.

[3] M. S. Kharasch, E. V. Jensen, W. H. Urry, J. Am. Chem. Soc. 1946, 68, 154-155.

[4] M. S. Kharasch, O. Reinmuth, W. H. Urry, J. Am. Chem. Soc. 1947, 69, 1105-1110.

[5] M. S. Kharasch, P. S. Skell, P. Fisher, J. Am. Chem. Soc. 1948, 70, 1055-1059.

[6] J. Byers, in Radic. Org. Synth. (Eds.: M.P. Sibi, P. Renaud), Wiley, 2008, pp. 72-89.

[7] D. P. Curran, in Free Radic. Synth. Biol. (Ed.: F. Minisci), Springer, Dordrecht, 1989, pp. 37-51.

[8] D. P. Curran, Synthesis 1988, 1988, 489-513.

[9] D. P. Curran, M. H. Chen, E. Spletzer, C. M. Seong, C. T. Chang, J. Am. Chem. Soc. 1989, 111, 8872-8878.

[10] D. P. Curran, C. M. Seong, J. Am. Chem. Soc. 1990, 112, 9401-9403.

[11] D. P. Curran, M. H. Chen, D. Kim, J. Am. Chem. Soc. 1989, 111, 6265-6276.

[12] E. Arceo, E. Montroni, P. Melchiorre, Angew. Chem. Int. Ed. 2014, 53, 12064-12068.

[13] C. Ollivier, T. Bark, P. Renaud, Synthesis 2000, 2000, 1598-1602.

[14] B. B. Noble, P. Nesvadba, M. L. Coote, J. Org. Chem. 2020, 85, 2338-2346.

[15] B. Quiclet-Sire, S. Z. Zard, in Radic. Synth. II (Ed.: A. Gansäuer), Springer, Berlin, Heidelberg, 2006, pp. 201236.

[16] S. Z. Zard, Helv. Chim. Acta 2019, 102, e1900134.

[17] T. Nakamura, H. Yorimitsu, H. Shinokubo, K. Oshima, Synlett 1998, 1998, 1351-1352.
[18] H. Yorimitsu, T. Nakamura, H. Shinokubo, K. Oshima, J. Org. Chem. 1998, 63, 8604-8605.

[19] H. Yorimitsu, T. Nakamura, H. Shinokubo, K. Oshima, K. Omoto, H. Fujimoto, J. Am. Chem. Soc. 2000, 122, 11041-11047.

[20] K. Nozaki, K. Oshima, K. Utimoto, Tetrahedron Lett. 1988, 29, 1041-1044.

[21] H. Yorimitsu, K. Oshima, in Radic. Org. Synth. (Eds.: P. Renaud, M.P. Sibi), Wiley-VCH Verlag GmbH, Weinheim, Germany, 2001, pp. 11-27.

[22] D. Bellus, Pure Appl. Chem. 1985, 57, 1827-1838.

[23] T. Pintauer, K. Matyjaszewski, Chem. Soc. Rev. 2008, 37, 1087-1097.

[24] W. T. Eckenhoff, T. Pintauer, Dalton Trans. 2011, 40, 4909-4917.

[25] J. M. Muñoz-Molina, T. R. Belderrain, P. J. Pérez, Eur. J. Inorg. Chem. 2011, 2011, 3155-3164.

[26] K. Severin, Chim. Int. J. Chem. 2012, 66, 386-388.

[27] W. Pu, D. Sun, W. Fan, W. Pan, Q. Chai, X. Wang, Y. Lv, Chem. Commun. 2019, 55, 4821-4824.

[28] T. Chatterjee, N. Iqbal, Y. You, E. J. Cho, Acc. Chem. Res. 2016, 49, 2284-2294.

[29] J. D. Nguyen, J. W. Tucker, M. D. Konieczynska, C. R. J. Stephenson, J. Am. Chem. Soc. 2011, 133, 41604163.

[30] C.-J. Wallentin, J. D. Nguyen, P. Finkbeiner, C. R. J. Stephenson, J. Am. Chem. Soc. 2012, 134, 8875-8884.

[31] S. Paria, M. Pirtsch, V. Kais, O. Reiser, Synthesis 2013, 45, 2689-2698.

[32] M. A. Cismesia, T. P. Yoon, Chem. Sci. 2015, 6, 54265434.

[33] P. Riente, M. A. Pericàs, ChemSusChem 2015, 8, 1841-1844.

[34] T. Courant, G. Masson, J. Org. Chem. 2016, 81, 69456952.

[35] G. Magagnano, A. Gualandi, M. Marchini, L. Mengozzi, P. Ceroni, P. G. Cozzi, Chem. Commun. 2017, 53, 1591-1594.

[36] L.-L. Mao, H. Cong, ChemSusChem 2017, 10, 44614464.

[37] J. K. Kochi, J. Am. Chem. Soc. 1962, 84, 1193-1197.

[38] T. V. RajanBabu, N. S. Simpkins, T. V. RajanBabu, Encycl. Reag. Org. Synth. 2005, DOI: 10.1002/047084289X.rd066.pub2.

[39] J. Lalevée, J. P. Fouassier, Encycl. Radic. Chem. Biol. Mater. 2012, DOI: 10.1002/9780470971253.rad003.

[40] H. Kiefer, T. G. Traylor, Tetrahedron Lett. 1966, 7, 6163-6168.

[41] J. Boukouvalas, S. Cren, P. Renaud, Encycl. Reag. Org. Synth. 2007, DOI: 10.1002/047084289X.rd062.pub2. 
[42] Y. P. Tsentalovich, L. V. Kulik, N. P. Gritsan, A. V. Yurkovskaya, J. Phys. Chem. A 1998, 102, 7975-7980.

[43] T. Nakamura, W. K. Busfield, I. D. Jenkins, E. Rizzardo, S. H. Thang, S. Suyama, J. Org. Chem. 2000, $65,16-23$.

[44] R. Meier, D. Trauner, Angew. Chem. Int. Ed. 2016, 55, 11251-11255.

[45] B. S. Matsuura, P. Kölle, D. Trauner, R. de VivieRiedle, R. Meier, ACS Cent. Sci. 2017, 3, 39-46.

[46] D. P. Curran, E. Bosch, J. Kaplan, M. Newcomb, J. Org. Chem. 1989, 54, 1826-1831.

[47] N. D. C. Tappin, W. Michalska, S. Rohrbach, P. Renaud, Angew. Chem. Int. Ed. 2019, 58, 14240-14244.

[48] M. Masnyk, Tetrahedron Lett. 1991, 32, 3259-3262.

[49] Millius, Lapointe, Renaud, Molecules 2019, 24, 4184.

[50] G. Povie, S. R. Suravarapu, M. P. Bircher, M. M. Mojzes, S. Rieder, P. Renaud, Sci. Adv. 2018, 4, eaat6031.

[51] M. Pirtsch, S. Paria, T. Matsuno, H. Isobe, O. Reiser, Chem. - Eur. J. 2012, 18, 7336-7340.

[52] S. Engl, O. Reiser, Eur. J. Org. Chem. 2020, 2020, $1523-1533$.

[53] L. R. Ryzhkov, J. Org. Chem. 1996, 61, 2801-2808.

[54] A. Fraind, R. Turncliff, T. Fox, J. Sodano, L. R. Ryzhkov, J. Phys. Org. Chem. 2011, n/a-n/a.

[55] M. Feldhues, H. J. Schäfer, Tetrahedron 1986, 42, 1285-1290.

[56] D. P. Curran, A. A. Martin-Esker, S. B. Ko, M. Newcomb, J. Org. Chem. 1993, 58, 4691-4695.

[57] Y. Gonen, L. A. Rajbenbach, A. Horowitz, Int. J. Chem. Kinet. 1977, 9, 361-369.

[58] L. Anthore-Dalion, Q. Liu, S. Z. Zard, J. Am. Chem. Soc. 2016, 138, 8404-8407.
[59] J. Maury, L. Feray, M. P. Bertrand, A. Kapat, P. Renaud, Tetrahedron 2012, 68, 9606-9611.

[60] V. Soulard, G. Villa, D. P. Vollmar, P. Renaud, J. Am. Chem. Soc. 2018, 140, 155-158.

[61] D. Meyer, E. Vin, B. Wyler, G. Lapointe, P. Renaud, Synlett 2015, 27, 745-748.

[62] Y.-X. Ji, L.-J. Wang, W.-S. Guo, Q. Bi, B. Zhang, Adv. Synth. Catal. 2020, 362, 1131-1137.

[63] G. A. Kraus, K. Landgrebe, Tetrahedron Lett. 1984, 25, 3939-3942.

[64] D. P. Curran, C. T. Chang, J. Org. Chem. 1989, 54, 3140-3157.

[65] J. O. Metzger, R. Mahler, Angew. Chem. Int. Ed. Engl. 1995, 34, 902-904.

[66] M. Iwasaki, N. Miki, Y. Ikemoto, Y. Ura, Y. Nishihara, Org. Lett. 2018, 20, 3848-3852.

[67] J. O. Metzger, R. Mahler, G. Francke, Liebigs Ann. 1997, 1997, 2303-2313.

[68] I. Triandafillidi, M. G. Kokotou, C. G. Kokotos, Org. Lett. 2018, 20, 36-39.

[69] G. R. Fulmer, A. J. M. Miller, N. H. Sherden, H. E. Gottlieb, A. Nudelman, B. M. Stoltz, J. E. Bercaw, K. I. Goldberg, Organometallics 2010, 29, 2176-2179.

[70] L. Gnägi, S. V. Martz, D. Meyer, R. M. Schärer, P. Renaud, Chem. - Eur. J. 2019, 25, 11646-11649.

[71] D. Meyer, H. Jangra, F. Walther, H. Zipse, P. Renaud, Nat. Commun. 2018, 9, 4888.

[72] J. Boukouvalas, J. M. Tanko, Encycl. Reag. Org. Synth. 2007, DOI: 10.1002/047084289X.rd067.pub2.

[73] J. L. Courtneidge, M. Bush, J. Chem. Soc. Perkin 1 1992, 1531-1538.

[74] D. Swern, Ed. , Organic Peroxides, WileyInterscience, New York, 1970. 
Methyl Radical Initiated Kharasch and Related

Reactions

Nicholas D. C. Tappin, and Philippe Renaud*

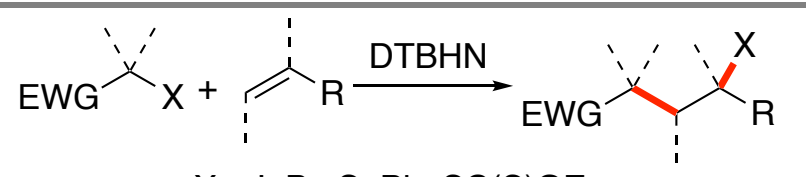

$\mathrm{X}=\mathrm{I}, \mathrm{Br}, \mathrm{SePh}, \mathrm{SC}(\mathrm{S}) \mathrm{OEt}$

$t-\mathrm{BuO}^{\prime}$
$\begin{aligned} & \mathrm{E}=\mathrm{N}^{\prime} \\ & \text { enters the } \\ & \text { radical chain }\end{aligned}$

